\title{
THE ROLE OF PERCEIVED COACHING BEHAVIOURS ON SPORT PERFORMANCE AMONG FEMALE AESTHETIC GROUP GYMNASTS
}

\author{
Andre Koka, Henri Tilga, Triin Põder, \\ Hanna Kalajas-Tilga, Vello Hein, Lennart Raudsepp \\ Institute of Sport Sciences and Physiotherapy, University of Tartu, Estonia
}

\begin{abstract}
This study aimed to test the relations of perceived autonomy-supportive and controlling behaviours from coaches with athletes' sport performance during competition in a context of female aesthetic group gymnastics. In line with self-determination theory, it was expected that the sequence of perceived psychological needs satisfaction and autonomous motivation, and psychological needs frustration and controlled motivation would mediate these relationships. Female aesthetic group gymnasts $(n=128)$ ages 11-20 years completed self-report measures of perceived autonomysupportive and controlling behaviours from coaches, athletes' needs satisfaction and needs frustration, including the need for novelty, as well as athletes' autonomous and controlled motivation. Athletes' objective performance during the competition was also obtained. Results from the single-indicator structural equation modelling analyses revealed a positive, indirect relationship between perceived autonomy-supportive behaviour from coaches and athletes' performance mediated by the sequence of needs satisfaction and autonomous motivation. Significant indirect relationship between perceived controlling behaviour from coaches and athletes' performance mediated by the sequence of needs frustration and controlled motivation was not followed. However, a negative direct relationship of controlled motivation, instigated by needs frustration, on athletes' performance was evident. Findings suggest that perceived autonomy-supportive behaviour from coaches is an essential antecedent to athletes' performance in a female aesthetic group gymnastics.
\end{abstract}

Keywords: autonomy support, controlling behaviour, psychological needs, motivation, sport performance, self-determination theory 


\section{INTRODUCTION}

It is well documented that coaches' behaviours are crucial determinants of athletes' motivation towards sport practice $[2,18,26]$. Specifically, coaches may either facilitate athletes' motivation by acting during the practice in an autonomy-supportive way or diminish it by acting, on the contrary, in a controlling way [2-4]. However, little is known about the relationships between motivational variables and sport performance, although the performance of athletes in a competition is considered as one of the most important outcomes in sport [16]. The aim of this study, therefore, was to test a model that integrates athletes' perceptions of autonomy-supportive and controlling behaviours from coaches, perceived satisfaction and frustration of basic psychological needs, qualitatively different types of motivation, and sport performance in a context of aesthetic group gymnastics in order to better understand the predictors of athletes' performance during competitions. In doing so, we relied on the framework of self-determination theory (SDT) $[6,33]$.

The central components of SDT $[6,33]$ are three innate basic psychological needs for autonomy (i.e., the need to feel choice and volition in one's actions), competence (i.e., the need to feel of being effective in one's actions), and relatedness (i.e., the need to feel positive and mutually satisfying relationships with significant others) that individuals strive to satisfy. Research guided by SDT in a sport context has shown that coaches' behaviours that are autonomy-supportive (e.g., acknowledging athletes' feelings, offering choice and rationale) are related to higher psychological needs satisfaction in their athletes [1,2], including female gymnasts $[9,23,24]$. Contrary, behaviours from coaches that can be characterised as controlling (e.g., using a coercive language, ignoring athletes' opinions) have demonstrated to be related to higher experience of psychological needs frustration in their athletes [2], as well as lower levels of need satisfaction for autonomy among female gymnasts [23].

The need for novelty (i.e., the desire to experience something not previously experienced or that deviates from everyday routine) has been recently proposed as a candidate basic psychological need [15]. Research has revealed the higher levels of perceived satisfaction of the need for novelty in students to be as a consequence of perceived autonomy support from teachers in physical education classes [25, 34]. In addition, satisfaction of the need for novelty has shown to be as an antecedent of various adaptive outcomes such as individuals' life satisfaction in a global level [15], vitality in a context of physical exercise [13], as well as students' intrinsic/autonomous motivation, vitality, and dispositional flow in physical education classes independent of 
the other three psychological needs satisfaction [7, 8, 14, 15, 25]. Taking these advantages related to the satisfaction of the need for novelty into the account, in this study we incorporated the need for novelty alongside with other three psychological needs introduced by SDT $[6,33]$ into the tested model.

A further proposition of SDT $[6,33]$ is that satisfaction or frustration of psychological needs determines the quality of motivation individuals experience when participating in a particular activity, and that psychological needs satisfaction and frustration mediate the relationship between perceived autonomy-supportive and controlling behaviours from significant others and motivation. Specifically, SDT distinguishes qualitatively different types of motivation, ranging from high quality motivation such as autonomous motivation (i.e., intrinsic motivation and identified regulation), over controlled motivation (i.e., introjected and external regulation), to amotivation (i.e., a lack of motivation) [6]. The review of research in a sport context guided by SDT have supported these tenets demonstrating that perceived autonomy-supportive behaviours from coaches are related to autonomous motivation towards sport in athletes through the psychological needs satisfaction, whereas perceived controlling behaviours form coaches are related to controlled motivation through the psychological needs frustration [27].

Paucity of work that have examined the relationship between athletes' motivation and sport performance during competitions revealed that athletes characterized by the least autonomous motivational profile exhibited the worst objective measure of performance among elite tennis players and swimmers [12]. Results of the study by Gillet et al. [11] showed that perceived autonomy-supportive behaviour from coaches facilitated national level judokas' autonomous motivation toward their sport, and that autonomous motivation promoted judokas' situational autonomous motivation before a competition, which, in turn, positively predicted their actual sport performance. Interestingly, however, the study by Karjane and Hein [22] showed that U-20 volleyball players from the winning team perceived their coaches to exhibit higher levels of controlling behaviour (i.e., intimidation, negative conditional regard, and excessive personal control) compared with players from the losing team. Moreover, winners scored significantly higher on external regulation, i.e., the most controlled form of motivation, compared with losers. The latter authors argued that coaches who wished their athletes to win the competition implemented more controlling motivational strategies to achieve the goal. Surprisingly, the athletes from the winning team did not perceive that their psychological needs for autonomy, competence, and relatedness would be thwarted significantly more than athletes 
from the losing team [22]. These contradictory results of studies exploring the role of perceived coaches' behaviours on actual sport performance of athletes encouraged us to conduct this additional research as it could identify important motivational determinants of athletes' sport performance. In addition, research among female gymnasts have focused mostly on the interplay between coaches' and teammates' behaviour, psychological need satisfaction, and well-being $[9,23,24]$, disregarding the links of motivational variables with an important outcome of sport, the actual performance of athletes during competitions.

Based on SDT and past work described above, a motivational model of sport performance in female aesthetic group gymnastics depicted in Figure 1 was proposed. Two hypotheses were tested. First, it was hypothesised that gymnasts' perceptions of autonomy-supportive behaviour from coaches would be positively and indirectly related to actual sport performance during a competition through the sequence of perceived psychological needs satisfaction and autonomous motivation. Second, it was hypothesised that gymnasts' perceptions of controlling behaviour from coaches would be negatively and indirectly related to actual sport performance during a competition through the sequence of perceived psychological needs frustration and controlled motivation.

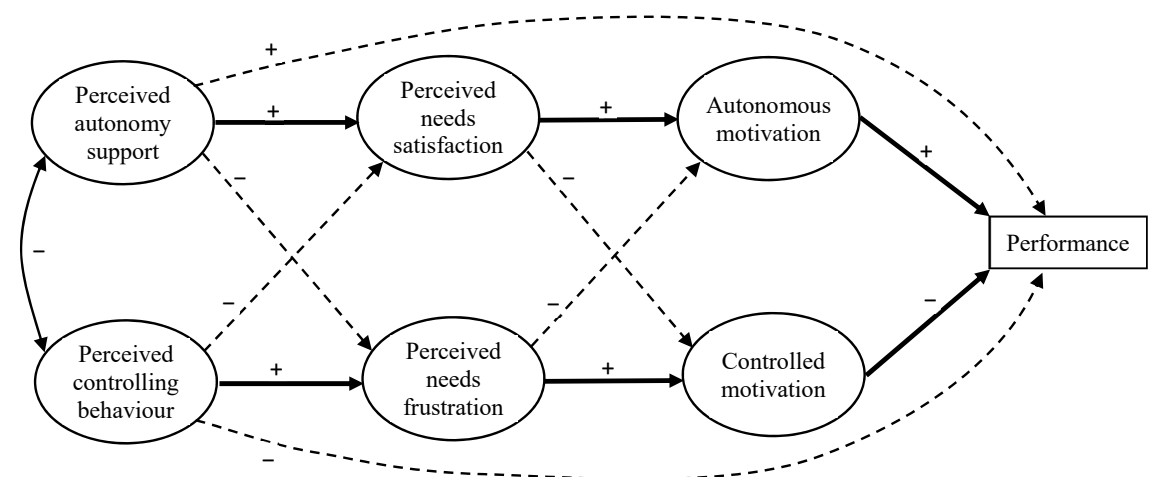

Figure 1. Hypothesized model depicting mediating role of the sequence of psychological needs satisfaction and needs frustration, and autonomous and controlled motivation in the relationship between perceived autonomy-supportive and controlling behaviour from coaches and athletes' performance score.

Broken lines indicate paths freed in the test of the model but expected to be zero. For clarity, the covariances between perceived needs satisfaction and perceived needs frustration, as well as between autonomous motivation and controlled motivation are omitted. "+" denotes a positive path and "-" denotes a negative path. 


\section{MATERIALS AND METHODS}

\section{Subjects and procedures}

Participants were 128 female aesthetic group gymnasts from 15 teams ranged in age from 11 to 20 years (age: $13.25 \pm 1.69$ yrs.). The current sample represented gymnasts of varying skill level to represent a broad range of experiences. All gymnasts had trained for at least 3 months with their current coach to adequately respond to questions about the behaviour of their coach.

After the approval from the local institutional review board, the coaches of aesthetic group gymnastics clubs in Estonia were contacted by e-mail. Gymnasts with parental consent and who agreed to participate completed the multi-section self-report questionnaire before or after a practice individually in an area of gym away from coaches. The multi-section questionnaire administered included self-report measures of perceived autonomysupportive and controlling behaviours from coaches, perceived needs satisfaction and needs frustration, and various types of motivation during the practice. Competition result of each athlete was recorded that was based on team's total scores achieved in the competition "Slonny Cup" held in December 2016.

\section{Measures}

\section{Perceived autonomy-supportive behaviour from coaches}

Gymnasts' perceptions of their coaches' autonomy-supportive behaviour was assessed with the 6-item Sport Climate Questionnaire (SCQ) [32]. An example item included "I feel that my coach provides me with choices and options". Responses were given on a seven-point Likert-type scale anchored by strongly disagree (1) to strongly agree (7). Previous research with young Estonian athletes has shown the SCQ to be a valid and reliable tool [21]. Cronbach's alpha coefficient for SCQ in this study was 0.76 .

\section{Perceived controlling behaviour from coaches}

Gymnasts' perceptions of their coaches' controlling behaviour was assessed using two four-item subscales (i.e., Intimidation and Negative conditional regard) from the Controlling Coach Behaviour Scale (CCBS) [4]. Example items are: "My coach shouts at me in front of others to make me do certain things" (Intimidation), and "My coach is less friendly with me if I don't make the effort to see things his/her way" (Negative conditional regard). 
Participants responded to the items on a seven-point Likert-type scale anchored by strongly disagree (1) to strongly agree (7). The factorial validity of the CCBS and its subscales has been previously provided $[4,22]$. In the present study, the Cronbach alphas for subscales of Intimidation and Negative conditional regard were 0.71 and 0.74 , respectively.

\section{Perceived psychological needs satisfaction and needs frustration}

Gymnasts' perceptions of psychological needs satisfaction and needs frustration during the practice were assessed by the Basic Psychological Need Satisfaction and Need Frustration scale (BPNSNF) [5], adapted for sport context in the present study. The stem was "During the practice..." and athletes responded to six 4-item subscales to measure perceptions of need satisfaction for autonomy (e.g., " ... I felt that the exercises reflect what I really want"), competence (e.g., " ... I felt capable at what I did”), and relatedness (e.g., " ... I felt that team members I care about also cared about me"), and need frustration for autonomy (e.g., "... I felt pressured to do too many exercises"), competence (e.g., " .. I felt insecure about my abilities"), and relatedness (e.g., " ... I felt excluded from the group I want to belong to"). Participants' responses were provided on a 5 -point scales $(1=$ strongly disagree and $5=$ strongly agree). Past studies have supported the tenability of the BPNSNF to adolescent sample [17,35]. In the present study, the Cronbach alphas for the subscales of need satisfaction for autonomy, competence, and relatedness were $0.68,0.73$, and 0.91 , respectively. Cronbach alphas for the subscales of need frustration for autonomy, competence, and relatedness were $0.33,0.78$, and 0.80 , respectively. Due to the low internal consistency of the subscale of need frustration for autonomy, it was excluded from further analyses.

\section{Perceived novelty need satisfaction and novelty need frustration}

Gymnasts' perceptions of the need satisfaction for novelty during practice were assessed by the Novelty Need Satisfaction Scale (NNSS) [15]. The stem for a six-item scale was "During the practice..." and an example item included "... I feel I do novel things". Support for the internal reliability of scores as well as factorial validity has provided in past research with Estonian adolescents [25]. In the current study, the Cronbach alpha demonstrated satisfactory internal consistency $(\alpha=0.74)$.

Gymnasts' perceptions of the need frustration for novelty during practice were assessed using a six-item scale derived from the NNSS [15], modified accordingly for the present study and referred hereafter as novelty 
need frustration scale (NNFS). An example item included "During the practice I feel that everything I do is as of old". The newly developed 6-item NNFS exhibited adequate factorial validity via confirmatory factor analysis $\left[\chi^{2}(9)=9.74, \mathrm{CFI}=0.99, \mathrm{NNFI}=0.99, \mathrm{RMSEA}=0.03, \mathrm{CI}_{90} \mathrm{RMSEA}=0.00-0.11\right]$ as well as internal consistency (Cronbach alpha $=0.72$ ). Responses to the both NNSS and NNFS were provided on a 5 -point scales ( $1=$ strongly disagree and $5=$ strongly agree).

\section{Motivational regulations towards aesthetic group gymnastics}

Gymnasts' different forms of motivational regulation towards aesthetic group gymnastics were assessed using the adapted version of the Sport Motivation Scale-II (SMS-II) [28]. Participants were asked to respond to the items using the common stem: "I take part in aesthetic group gymnastics ..., followed by different reasons: intrinsic motivation (e.g., "... because it gives me pleasure to learn more about this sport"); identified regulation (e.g., "... because I have chosen this sport as a way to develop myself"); introjected regulation (e.g., "... because I would feel bad about myself if I did not take the time to do it"); external regulation (e.g. "... because people I care about would be upset with me if I did not"), and amotivation (e.g., "I don't know anymore; I have the impression that I am incapable of succeeding in this sport"). In this study, the integrated regulation (e.g., "... because practicing this sport reflects the essence of whom I am") was not measured as it is difficult to empirically distinguish from intrinsic motivation and identified regulation through self-reports in adolescents [36]. All subscales consist of three items. Responses were assessed on a 7-point Likert scale ranging from 1 (strongly disagree) to 7 (strongly agree). Past work with Estonian adolescent athletes has provided support for internal reliability of subscale scores and factorial structure of the SMS-II [22]. In the present study, Cronbach alphas for intrinsic motivation, identified regulation, introjected regulation (after the removal of the Item 2 “... because I would not feel worthwhile if I did not"), external regulation (after the removal of the Item 1 "... because people around me reward me when I do"), and amotivation were $0.69,0.70,0.57$, 0.73 , and 0.80 , respectively.

\section{Performance score}

At the end of 2016, in December, gymnasts who took part in this study participated at the female aesthetic group gymnastics competition "Slonny Cup". Performance score of each athlete was based on one's team final ranking and total score obtained during the competition. The performance of each team 
was scored by three judge panel (technical jury, artistic jury, and executive jury) who had no connections with teams and who were not informed about the purpose of the study. The highest total score the team can obtain is 20.00 points and consists of (a) technical value that can vary from 0 to 6.0 points, (b) artistic value varying from 0 to 4.0 points, and (c) execution value varying from 0 to 10.0 points.

\section{Statistical analyses}

The data were analysed using SPSS Version 23 and AMOS Version 23 statistical software. The preliminary analysis included the calculation of descriptive statistics and correlations between all the measured variables. The main analysis included the test of hypothesised relationships among study variables using the single-indicator structural equation modelling (SEM). The single-indicator SEM approach was adopted because the hypothesised model involved several multi-item scales that may lead to convergence issues when using the full latent variable SEM analysis with multiple-indicator factors with relatively small sample size. It has been suggested that single-indicator SEM resolves convergence issues and generates reliable model parameter estimates that are similar to full-latent variable SEM [19]. Prior to the SEM, average scores for each study variable were computed by averaging the items of each scale. Furthermore, intimidation and negative conditional regard were aggregated to represent a composite score of perceived controlling behaviour. Perceived need satisfaction for autonomy, competence, relatedness, and novelty were used to compute a composite score of perceived needs satisfaction, whereas perceived need frustration for competence, relatedness, and novelty were used to compute a composite score of perceived needs frustration. Finally, intrinsic motivation and identified motivation were aggregated to represent a composite score of autonomous motivation, and introjected and external motivation were used to compute a composite score of controlled motivation. The construct of amotivation was not considered in the test of the hypothesised model. The single indicator for study variables, except for athletes' performance score, were then generated by taking the computed average score of each variable and accounting for the error variance using the following formula: (1-reliability) * sample variance [29].

The following indices were used to assess the adequacy of the fit of the hypothesized model: Comparative Fit Index (CFI), Non-Normed Fit Index (NNFI), and Root Mean Squared Error of Approximation (RMSEA) with its $90 \%$ confidence intervals $\left(\mathrm{CI}_{90}\right)$. The values $\geq 0.95$ for $\mathrm{CFI}$ and NNFI, and 
the value $\leq 0.06$ for RMSEA were considered indicative of an acceptable fit [20]. The SEM was accompanied with bootstrapping analysis to detect the significance of the indirect effects in the model. If the $95 \%$ confidence interval $\left(\mathrm{CI}_{95}\right)$ for the indirect effect does not contain the zero, then the indirect effect can be concluded as statistically significant [30].

\section{RESULTS}

\section{Preliminary analysis}

Descriptive statistics and correlations between all the measures are presented in Table 1. Values for skewness ranged from -2.02 to 0.80 and values for kurtosis ranged from -0.57 to 4.32 , suggesting that the distribution of all the measures were within the acceptable ranges [10]. 


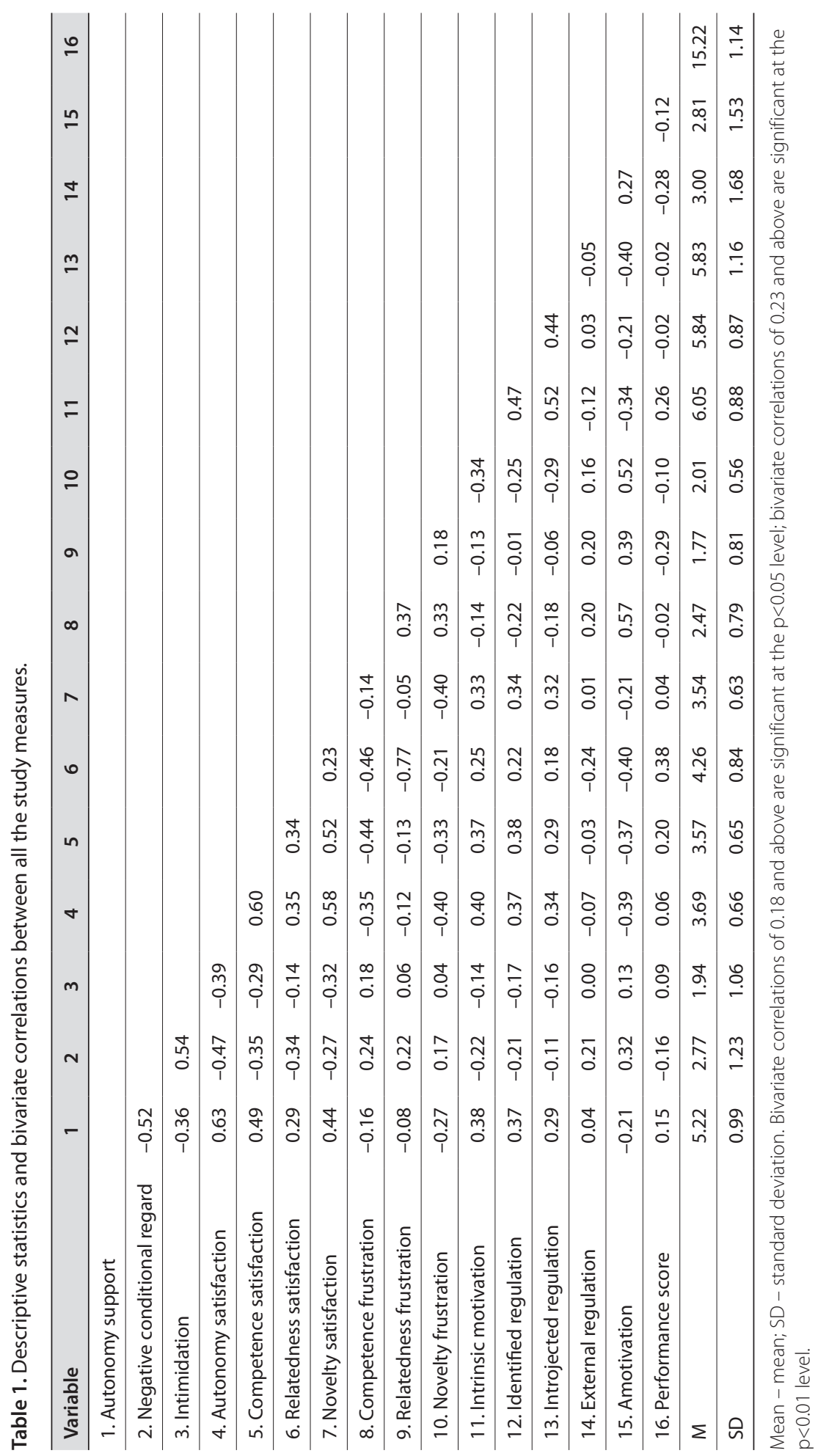




\section{Main analysis}

The hypothesized model exhibited good fit to the data: $\chi^{2}(6)=8.10, p=0.23$, $\mathrm{CFI}=0.99, \mathrm{NNFI}=0.96, \mathrm{RMSEA}=0.054, \mathrm{CI}_{90}$ for $\mathrm{RMSEA}$ range $=0.000-0.138$. The standardized path coefficients for the free parameters are shown in Figure 2. The model accounted for $55 \%, 9 \%, 38 \%, 17 \%$, and $37 \%$ of the variance in perceived needs satisfaction, perceived needs frustration, autonomous motivation, controlled motivation, and performance score, respectively.

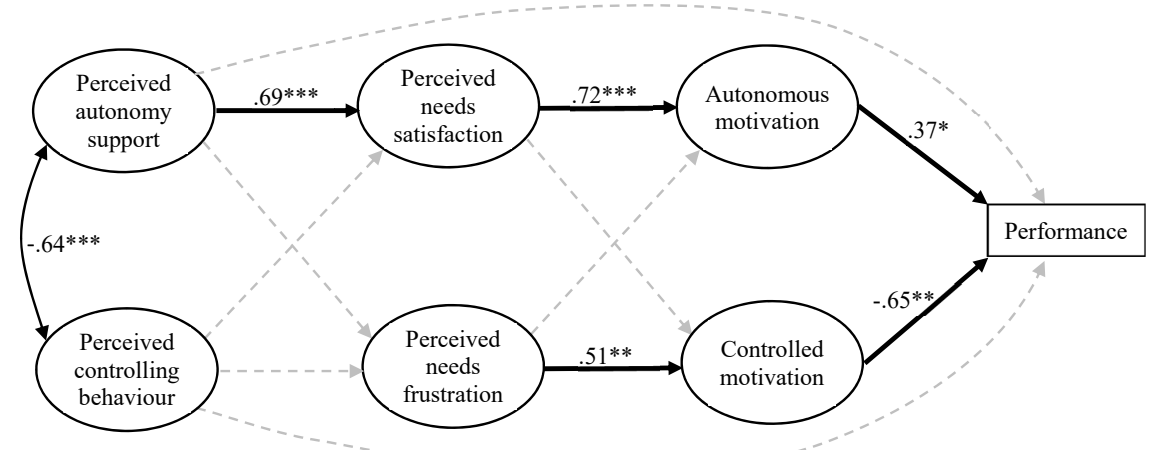

Figure 2. Results of the single-indicator structural equation model measuring the mediating role of the sequence of psychological needs satisfaction and needs frustration, and autonomous and controlled motivation in the relationship between perceived autonomy-supportive and controlling behaviour from coaches and athletes' performance score.

The feint broken lines indicate non-significant paths. For clarity, covariances between perceived needs satisfaction and perceived needs frustration, as well as between autonomous motivation and controlled motivation are omitted. Covariances of the disturbance terms were as follows: $r_{\text {needs satisfaction-needs frustration }=}$ $-0.78^{* * *}$, rautonomous motivation-controlled motivation $=0.48^{* *} .{ }^{*} p<0.05,{ }^{* *} p<0.01,{ }^{* * *} p<0.001$.

As hypothesized, perceived autonomy-supportive behaviour from coaches had direct and positive effect on perceived needs satisfaction $(\beta=0.69$, $\mathrm{p}<0.001)$. The direct and significant effect of perceived controlling behaviour from coaches on perceived needs frustration $(\beta=0.21, \mathrm{p}>0.05)$ did not emerged, as was hypothesized. Perceived needs satisfaction had direct and positive effect on autonomous motivation $(\beta=0.72, \mathrm{p}<0.001)$, and perceived need frustration had direct and positive effect on controlled motivation $(\beta=0.51, p<0.01)$, as expected. As was expected, autonomous motivation had significant direct and positive effect on performance score $(\beta=0.37, p<0.05)$, whereas controlled motivation had significant direct and negative effect on performance score $(\beta=-0.65, \mathrm{p}<0.01)$.

Based on the examination of significant single paths shown in Figure 2, the significance of one specific indirect effect from perceived autonomy- 
supportive behaviour to performance score via the sequence of perceived needs satisfaction and autonomous motivation was estimated. Results revealed that the specific indirect effect of perceived autonomy-supportive behaviour from coach on performance score via the sequence of perceived needs satisfaction and autonomous motivation was significant and positive $\left(B=0.25 ; \mathrm{CI}_{95}=0.03,0.93 ; \beta=0.18 ; \mathrm{p}<0.05\right)$. Since perceived controlling behaviour from coaches did not have significant effect on any of the variable in the model, none of the specific indirect effect from perceived controlling behaviour form coaches to performance score was examined.

\section{DISCUSSION}

This study aimed to explain the role of perceived autonomy-supportive and controlling behaviours from coaches on actual sport performance during a competition through the perceived satisfaction and frustration of basic psychological needs, including the need for novelty, and qualitatively different motivation among female aesthetic group gymnasts. The findings of the present study supported one out of the two hypotheses. Specifically, results revealed that perceived autonomy-supportive behaviours from coaches significantly contributed to the actual sport performance in a competition of female aesthetic group gymnasts through the motivational variables. This is in line with the tenets of SDT $[6,33]$, as well as past work in a sport context [11, 12,27], including female gymnastics [9, 23, 24]. Results of the current study further emphasise the important role of interaction of coaches with their athletes in an autonomy-supportive way during the practice in order to elicit the better athletes' performance in a competition. From the applied perspective, the coaches of female aesthetic group gymnasts are encouraged to implement autonomy-supportive behaviours such as adopting the perspectives and feelings of their athletes, giving a good rationale for proposed tasks and exercises, providing choice, and encouraging selfendorsed action [31].

As was already noted, the second hypothesis of the present study did not find support. Specifically, the expected negative indirect effect of perceived controlling behaviours from coaches on actual sport performance in a competition through the perceived frustration of psychological needs, including the need for novelty, and controlled motivation was not significant. It is noteworthy that the perceived controlling behaviour from coaches did not substantially contributed to the perceived frustration of psychological needs among female aesthetic group gymnasts during the practice, the finding that is inconsistent with the tenets of SDT $[6,33]$ and past work in sport $[2,27]$. 
The possible reason for this finding may be that coaches in this study rarely used controlling motivational strategies such as negative conditional regard and intimidation during the practice. It should also be noted that mean scores for athletes' perceptions of negative conditional regard and intimidation were low relative to the scale midpoint that may reflect the low levels of actual controlling behaviours from coaches.

Consistent with SDT $[6,33]$ and past work in sport [27], the more female gymnasts in this study felt their basic psychological needs to be frustrated the more they practiced their sport for pressured reasons (i.e., controlled motivation). Moreover, doing the activity for pressured reasons lead to the worse performance score in a competition, the result that is consistent with previous study with elite tennis players and swimmers [12]. Although the results of the present study did not reveal the detrimental indirect effect of perceived controlling behaviours from coaches to female gymnasts' actual performance in a competition, coaches are advised to avoid controlling motivational strategies such as negative conditional regard and intimidation when communicating with their athletes. Specifically, coaches of female aesthetic group gymnasts are advised to avoid behaviours such as being less supportive to athletes if they have not act as the coach wanted (i.e., negative conditional regard) and shouting at athletes in front of others to push them to do certain things they want (i.e., intimidation). These behaviours may likely to frustrate basic psychological needs, and consequently diminish athletes' will and motivation, that have demonstrated in previous studies in a sport context $[2,23]$.

Although the present study provided some interesting results in terms of the role of perceived coaching behaviours on actual sport ferformance among female aesthetic group gymnasts, there are some limitations with this study that should be noted. First, this study was cross-sectional in nature that does not allow us to draw conclusions about the direction of the relationships. The hypotheses of the present study were formulated based on the framework of SDT $[6,33]$ that assume the unidirectional relationships with the flow from perceived coaching behaviors to athletes' sport performance mediated by the sequence of psychological needs and motivation. However, it is also likely that relationships between above variables are bidirectional such that perceived coaching behaviours elicit the athletes' performance in a competition and vice versa that a 'good' versus 'bad' performance in a competition may influence the way athletes' perceive their coaches behavious. Future studies could adopt a cross-lagged panel design assessing variables of interest at two or more points in time and analyse for reciprocal relations between the variables over time. 
Second, in terms of assessing perceived coaching behaviours, the present study relied entirely on athletes' self-reports. Researchers [17] have suggested to adopt a multi-informant (i.e., coach, athletes, and external observer) perspective in order to obtain a more accurate picture of whether the coach exhibits autonomy-supportive and controlling behaviours, respectively, and to what extent. Therefore, future studies would do well by incorporating both coaches' and athletes' self-reports, as well as ratings of external observers when examining predictors of athletes' actual sport performance during competitions.

Third, some of the subscales from the BPNSNF (i.e., autonomy need frustration) and SMS-II (i.e., introjected regulation and external regulation) showed low or very low reliability coefficients in this study. Future studies assessing these constructs among female aesthetic group gymnasts should consider rephrasing the identified problematic items to increase the internal reliability of these subscales. Finally, in the present study the past performance in competitions and ability differences of athletes were not controlled for. As has been suggested previously [12], in order to strengthen the validity of conclusions drawn from the results, it would be useful to do so in future studies.

In sum, findings of the present study contribute to our understanding of the mechanism through which the perceived autonomy-supportive and controlling behaviours from coaches influence actual sport performance during a competition among female aesthetic group gymnasts. The findings suggest that perceived autonomy-supportive behaviour is an essential antecedent to actual sport performance mediated by the sequence of psychological needs satisfaction and autonomous motivation among female aesthetic group gymnasts. In addition, although the negative indirect effect of perceived controlling behaviour from coaches on athletes' actual sport performance via the sequence of psychological needs frustration and controlled motivation was not detected, athletes who practiced for pressured or controlled motives demonstrated worse performance score in a competition.

\section{REFERENCES}

1. Amorose AJ, Anderson-Butcher D. (2007) Autonomy-supportive coaching and self-determined motivation in high school and college athletes: A test of selfdetermination theory. Psychol Sport Exerc, 8(5): 654-670.

https://doi.org/10.1016/j.psychsport.2006.11.003

2. Bartholomew KJ, Ntoumanis N, Ryan RM, Bosch JA, Thøgersen-Ntoumani C. (2011) Self-determination theory and diminished functioning: The role of interpersonal control and psychological need thwarting. Pers Soc Psychol Bull, 37(11): 1459-1473. https://doi.org/10.1177/0146167211413125 
3. Bartholomew KJ, Ntoumanis N, Thøgersen-Ntoumani C. (2009) A review of controlling motivational strategies from a self-determination theory perspective: Implications for sports coaches. Int Rev Sport Exer P, 2(2): 215-233. https://doi.org/10.1080/17509840903235330

4. Bartholomew KJ, Ntoumanis N, Thøgersen-Ntoumani C. (2010) The controlling interpersonal style in a coaching context: Development and initial validation of a psychometric scale. J Sport Exerc Psychol, 32(2): 193-216.

https://doi.org/10.1123/jsep.32.2.193

5. Chen B, Vansteenkiste M, Beyers W, Boone L, Deci EL, Van der Kaap-Deeder J, Duriez B, Lens W, Matos L, Mouratidis A, Ryan RM, Sheldon KM, Soenens B, Van Petegem S, Verstuyf J. (2015) Basic psychological need satisfaction, need frustration, and need strength across four cultures. Motiv Emot, 39(2): 216-236. https://doi.org/10.1007/s11031-014-9450-1

6. Deci EL, Ryan RM. (2000) The "what" and "why" of goal pursuits: Human needs and the self-determination of behavior. Psychol Inq, 11(4): 227-268. https://doi.org/10.1207/S15327965PLI1104_01

7. Fernández-Espínola C, Almagro BJ, Tamayo-Fajardo JA, Sáenz-López P. (2020) Complementing the self-determination theory with the need for novelty: Motivation and intention to be physically active in physical education students. Front Psychol, 11: 1535. https://doi.org/10.3389/fpsyg.2020.01535

8. Fierro-Suero S, Almagro BJ, Sáenz-López P, Carmona-Márquez J. (2020) Perceived novelty support and psychological needs satisfaction in physical education. Int J Environ Res Pub He, 17(11): 4169. https://doi.org/10.3390/ijerph17114169

9. Gagne M, Ryan RM, Bargmann K. (2003) Autonomy support and need satisfaction in the motivation and well-being of gymnasts. J Appl Sport Psychol, 15(4): 372-390. https://doi.org/10.1080/714044203

10. George D, Mallery M. (2010) SPSS for Windows step by step: A simple guide and reference, 17.0 update. Boston: Pearson

11. Gillet N, Vallerand RJ, Amoura S, Baldes B. (2010) Influence of coaches' autonomy support on athletes' motivation and sport performance: A test of the hierarchical model of intrinsic and extrinsic motivation. Psychol Sport Exerc, 11(2): 155-161. https://doi.org/10.1016/j.psychsport.2009.10.004

12. Gillet N, Vallerand RJ, Rosnet E. (2009) Motivational clusters and performance in a real-life setting. Motiv Emot, 33(1): 49-62.

https://doi.org/10.1007/s11031-008-9115-z

13. González-Cutre D, Romero-Elías M, Jiménez-Loaisa A, Beltrán-Carrillo VJ, Hagger MS. (2020) Testing the need for novelty as a candidate need in basic psychological needs theory. Motiv Emot, 44(2): 295-314.

https://doi.org/10.1007/s11031-019-09812-7

14. González-Cutre D, Sicilia A. (2019) The importance of novelty satisfaction for multiple positive outcomes in physical education. Eur Phys Educ Rev, 25(3): 859-875. https://doi.org/10.1177/1356336X18783980 
15. González-Cutre D, Sicilia A, Sierra AC, Ferriz R, Hagger MS. (2016) Understanding the need for novelty from the perspective of self-determination theory. Pers Individ Differ, 102: 159-169. https://doi.org/10.1016/j.paid.2016.06.036

16. Gould D, Dieffenbach K, Moffett A. (2002) Psychological characteristics and their development in Olympic champions. J Appl Sport Psychol, 14(3): 172-204. https://doi.org/10.1080/10413200290103482

17. Haerens L, Aelterman N, Vansteenkiste M, Soenens B, Van Petegem S. (2015) Do perceived autonomy-supportive and controlling teaching relate to physical education students' motivational experiences through unique pathways? Distinguishing between the bright and dark side of motivation. Psychol Sport Exerc, 16: 26-36. https://doi.org/10.1016/j.psychsport.2014.08.013

18. Horn TS. (2002) Coaching effectiveness: research findings and future directions. In Horn TS. (ed). Advances in sport psychology (2nd ed.). Champaign, IL: Human Kinetics, 309-354.

19. Hsiao Y-Y, Kwok O-M, Lai MH. (2018) Evaluation of two methods for modeling measurement errors when testing interaction effects with observed composite scores. Educ Psychol Meas, 78(2): 181-202. https://doi.org/10.1177/0013164416679877

20. Hu L, Bentler PM. (1999) Cutoff criteria for fit indexes in covariance structure analysis: Conventional criteria versus new alternatives. Struct Equ Modeling, 6(1): 1-55. https://doi.org/10.1080/10705519909540118

21. Jõesaar H, Hein V, Hagger MS. (2012) Youth athletes' perception of autonomy support from the coach, peer motivational climate and intrinsic motivation in sport setting: One-year effects. Psychol Sport Exerc, 13(3): 257-262.

https://doi.org/10.1016/j.psychsport.2011.12.001

22. Karjane K, Hein V. (2015) Controlling coaches' behaviour, psychological need thwarting, motivation and results of the volleyball competitions. Acta Kinesiol Univ Tartu, 21: 51-60. https://doi.org/10.12697/akut.2015.21.05

23. Kipp LE, Weiss MR. (2013) Social influences, psychological need satisfaction, and well-being among female adolescent gymnasts. Sport Exerc Perform Psychol, 2(1): 62-75. https://doi.org/10.1037/a0030236

24. Kipp LE, Weiss MR. (2015) Social predictors of psychological need satisfaction and well-being among female adolescent gymnasts: A longitudinal analysis. Sport Exerc Perform Psychol, 4(3): 153-169.

https://doi.org/10.1037/spy0000033

25. Koka A, Tilga H, Hein V, Kalajas-Tilga H, Raudsepp L. (in press) A multidimensional approach to perceived teachers' autonomy support and its relationship with intrinsic motivation of students in physical education. Int J Sport Psychol. https://doi.org10.7352/IJSP.2020.51.

26. Mageau GA, Vallerand RJ. (2003) The coach-athlete relationship: a motivational model. J Sports Sci, 21(11): 883-904. https://doi.org/10.1080/0264041031000140374 
27. Matosic D, Ntoumanis N, Quested E. (2016) Antecedents of need supportive and controlling interpersonal styles from a self-determination theory perspective: A review and implications for sport psychology research. In Raab M, Wylleman P, Seiler R, Elbe A-M, Hatzigeorgiadis A. (eds.) Sport and Exercise Psychology Research: From Theory to Practice. Elsevier: Academic Press, 145-180. https://doi.org/10.1016/B978-0-12-803634-1.00007-8

28. Pelletier LG, Rocchi MA, Vallerand RJ, Deci EL, Ryan RM. (2013) Validation of the revised sport motivation scale (SMS-II). Psychol Sport Exerc, 14(3): 329-341. https://doi.org/10.1016/j.psychsport.2012.12.002

29. Petrescu M. (2013) Marketing research using single-item indicators in structural equation models. J Market Anal, 1(2): 99-117. https://doi.org/10.1057/jma.2013.7

30. Preacher KJ, Hayes AF. (2008) Asymptotic and resampling strategies for assessing and comparing indirect effects in multiple mediator models. Behav Res Methods, 40(3): 879-891. https://doi.org/10.3758/BRM.40.3.879

31. Reeve J, Jang HS. (2006) What teachers say and do to support students' autonomy during a learning activity. J Educ Psychol, 98(1): 209-218. https://doi.org/10.1037/0022-0663.98.1.209

32. Reinboth M, Duda JL, Ntoumanis N. (2004) Dimensions of coaching behavior, need satisfaction, and the psychological and physical welfare of young athletes. Motiv Emot, 28(3): 297-313. https://doi.org/10.1023/B:MOEM.0000040156.81924.b8

33. Ryan RM, Deci EL. (2017) Self-determination theory: Basic psychological needs in motivation, development, and wellness. New York: Guilford.

34. Sevil-Serrano J, Aibar A, Abos A, Generelo E, Garcia-Gonzalez L. (in press) Improving motivation for physical activity and physical education through a school-based intervention. J Exp Educ.

35. Tilga H, Hein V, Koka A, Hagger MS. (2020) How physical education teachers' interpersonal behaviour is related to students' health-related quality of life. Scand J Educ Res, 64(5): 661-676.

https://doi.org/10.1080/00313831.2019.1595718

36. Vallerand RJ, Fortier MS. (1998) Measures of intrinsic and extrinsic motivation in sport and physical activity: A review and critique. In Duda JL. (ed.) Advances in sport and exercise psychology measurement. Morgantown, WV: Fitness Information Technology, 91-101.

\section{Correspondence to:}

Andre Koka

Institute of Sport Sciences and Physiotherapy

Faculty of Medicine

University of Tartu

4 Ujula street, EE 51008 Tartu, Estonia

E-mail: andre.koka@ut.ee 